\title{
Comparison of Immune Effects Between Brucella Recombinant Omp10-Omp28-L7/L12 Proteins Expressed in Eukaryotic and Prokaryotic Systems
}

OPEN ACCESS

Edited by:

Michael Kogut,

Agricultural Research Service,

United States Department of

Agriculture, United States

Reviewed by:

Rakesh Bhatnagar,

Jawaharlal Nehru University, India

Venkatramana D. Krishna,

University of Minnesota Twin Cities,

United States

Hui Zhang,

Shihezi University, China

*Correspondence:

Duo Peng

dpeng@hsph.harvard.edu

Liping Hu

hxyhlp@sina.com

Kai Wei

weikaisdau@163.com

Ruiliang Zhu

zhur@sdau.edu.cn

Specialty section: This article was submitted to Veterinary Infectious Diseases,

a section of the journal

Frontiers in Veterinary Science

Received: 28 April 2020

Accepted: 20 July 2020

Published: 18 September 2020

Citation:

Zhu L, Wang Q, Wang Y, Xu Y, Peng $D$, Huang $H, H u L$, Wei $K$ and Zhu R (2020) Comparison of Immune

Effects Between Brucella Recombinant Omp10-Omp28-L7/L12 Proteins Expressed in Eukaryotic and Prokaryotic Systems.

Front. Vet. Sci. 7:576. doi: 10.3389/fvets.2020.00576
Lin Zhu ${ }^{1,2}$, Qiuju Wang ${ }^{1,2}$, Yujian Wang ${ }^{1,2}$, Yulin $\mathrm{Xu}^{1,2}$, Duo Peng ${ }^{3 *}, \mathrm{He}$ Huang ${ }^{4}$, Liping Hu ${ }^{5 *}$, Kai Wei ${ }^{1,2 \star}$ and Ruiliang Zhu ${ }^{1,2 *}$

\footnotetext{
'Shandong Provincial Key Laboratory of Animal Biotechnology and Disease Control and Prevention, Shandong Agricultural University, Tai'an, China, ${ }^{2}$ Shandong Provincial Engineering Technology Research Center of Animal Disease Control and Prevention, Shandong Agricultural University, Tai'an, China, ${ }^{3}$ Department of Immunology and Infectious Diseases, Harvard T.H. Chan School of Public Health, Boston, MA, United States, ${ }^{4}$ Shandong New Hope Liuhe Co., Ltd., New Hope Group, Qingdao, China, ${ }^{5}$ Animal Disease Prevention and Control Center of Shandong Province, Animal Husbandry and Veterinary Bureau of Shandong Province, Jinan, China
}

Brucella, a genus of bacteria that causes brucellosis, infects and threatens domestic animals, and humans in endemic areas. Presently, some live attenuated vaccines of Brucella are used to immunize livestock; however, these vaccines are pathogenic to humans, can provoke abortion when administered to pregnant livestock, and induce antibodies in vaccinated livestock that affect the diagnosis of field infection. It is, therefore, very important for improving the safety and immune protection effects of Brucella vaccine. Currently, recombinant protein-based subunit vaccines are considered promising safe and effective alternatives against brucellosis. Here, we separately expressed the recombinant Omp10-Omp28-L7/L12 proteins of Brucella using eukaryotic and prokaryotic expression systems, which were then used as immunogens for evaluating their immune responses. Taishan Pinus massoniana pollen polysaccharides (TPPPS), an already verified natural adjuvant, was utilized to evaluate the immune conditioning effect on the recombinant proteins. Antibody levels, spleen lymphocyte proliferation, percentages of $\mathrm{CD}^{+}$and $\mathrm{CD}^{+}{ }^{+} \mathrm{T}$ cells, and cytokine secretion in mice were examined after three successive immunizations. The protective effects against Brucella challenge were also evaluated in mice, and used a live vaccine as a positive control. The results indicated that the immune responses of the recombinant Omp10-Omp28-L7/L12 protein groups were significantly higher than those of the PBS control group. The recombinant Omp10-Omp28-L7/L12 protein expressed in Pichia pastoris (P. pastoris) exhibited a slightly higher expression level and immunogenicity than that expressed in Escherichia coli (E. coli), and the Omp10-Omp28-L7/L12 ( . pastoris) + TPPPS group provided the most pronounced immune effect. The protective results showed that the recombinant Omp10-Omp28-L7/L12 proteins expressed in the two expression systems had significantly better protective effects against Brucella melitensis challenge compared with the negative control, and the addition 
of TPPPS adjuvant could significantly improve the protective effects of subunit vaccines. However, we also noticed that all of the evaluated subunit vaccines induced less protection than the $B$. melitensis M5 live vaccine. These results indicate that the combination of recombinant Omp10-Omp28-L7/L12 antigen and TPPPS adjuvant shows potential as an effective brucellosis subunit vaccine, and $P$. pastoris is a preferred expression system to prepare this recombinant subunit antigen.

Keywords: Brucella, subunit vaccine, Pichia pastoris, recombinant protein, adjuvant

\section{INTRODUCTION}

Brucellosis is a common zoonosis caused by certain species of the Brucella genus, which are facultative, intracellular, Gramnegative pathogens (1). Brucella leads to abortion in livestock and wildlife and causes multiple illnesses in humans (2). In China, vaccination and eradication are the principles of comprehensive measures to prevent and control brucellosis. Vaccination of susceptible animals is known as essential to control brucellosis in order to protect public health and prevent economic loss (3). In recent decades, China has used several live Brucella vaccines. For example, B. melitensis M5-90 is one vaccine strain mainly used in goats, whereas $B$. melitensis Rev. 1 is used to protect goats and sheep from $B$. melitensis infection (4). Additionally, strains 19 (S19) (5), 82 (S82) (6), and B. abortus RB51 are the three main vaccines believed to protect cattle from $B$. abortus infection. The live brucellosis vaccines can effectively reduce the prevalence of brucellosis in natural hosts, but with known disadvantages: (1) they are unstable and sometimes cause brucellosis associated with vaccines; (2) we cannot distinguish between vaccine reactions and natural infections using antibody detection; (3) some live vaccines can cause allergic reactions similar to strong Brucella infection; and (4) some live Brucella vaccines cannot be used in pregnant or lactating animals (7). For these reasons, new strategies or improved vaccines against Brucella must be developed.

Subunit vaccines that are dependent on antigen identification and expressed in eukaryotic or prokaryotic systems have been widely developed $(3,8)$. An advantage of recombinant subunit vaccines is that they can not only induce high levels of antibody but also eliminate the safety issues associated with live vaccines (9). Moreover, subunit vaccines can be better controlled because they are more homogenous, therefore, wild and vaccine strain infections can be distinguished by detecting antibodies against subunits and other antigens. Although an adjuvant is usually required with subunit vaccines and they are relatively less protective than conventional vaccines because of their limited antigenic epitopes, subunit vaccines are still believed to be a safer and potential option in the development of the next-generation vaccine (10). Currently, some subunit protein antigens of Brucella, particularly outer membrane proteins (Omps) and ribosomal proteins expressed in E. coli, serve as vaccine candidates, such as Omp10 (11), Omp16 (12), Omp25 (13), Omp31 (14), Omp2b (15), Omp28 (BP26) (11), and L7/L12 $(16,17)$. These have all shown good immunoreactivity and protective effects under laboratory conditions $(18,19)$.
Notably, previous studies on Brucella subunit vaccines showed that bivalent vaccines (based on recombinant L7/L12-Omp16 or L7/L12-P39 subunits) induce stronger immune responses and better protection against Brucella than univalent vaccines (20, 21). Cassataro et al. confirmed a BLS-based chimera decorated with 10 copies of a 27-amino acid epitopes derived from Omp31, which not only induced peptide- and BLS-specific Th1 and cytotoxic T responses but also caused a strong humoral response to the inserted peptide (22). In another study performed by Golshani et al., the rL7/L12-TOmp31 may be a new potential antigen candidate that can be used to develop subunit vaccines against $B$. melitensis and B. abortus (16). Nevertheless, other antigen combinations should be tested to determine if they can produce better protection.

In previous studies, the outer membrane proteins Omp10 and Omp28 and ribosomal protein L7/L12 were expressed separately in various systems and were shown good immunogenicity (11, 23). The Omp10 is a surface-exposed lipoprotein, which is an important immunogenic protein of Brucella and is strongly conserved and expressed in all known Brucella species and their biovars (24). Moreover, Omp10 is also considered to be related to the virulence of Brucella (25), and studies have shown that it can induce protective cellular immunity. Omp28 exists in different Brucella species, it is a conservative protein. It is a soluble protein that can be released from the inside of the cell to the outside, and it has the advantage of being easy to detect compared with the fixed Omps $(26,27)$. Not only can it react with IgG antibody, but it can also induce a protective immune response (28). Omp28 has been known as a subunit vaccine candidate and a serological diagnostic antigen (29). The ribosomal protein L7/L12 has been identified as an immunodominant antigen that is considered a priority antigen in the development of Brucella subunit vaccines (30), and some studies have been done using L7/L12 in subunit vaccines (23). It has been found that L7/L12 can specifically stimulate monocytes of infected animals and promote the transcription and expression of IFN- $\gamma$, which plays an auxiliary role in immune protection (31). L7/L12-based vaccines have the most significant resistance to infection. Thus, in this study, we selected three antigen proteins, Omp10, Omp28, and L7/L12, and studied their compound immunogenicity based on a fusion expression scheme. We expressed the Omp10-Omp28-L7/L12 fusion proteins in the $P$. pastoris eukaryotic expression system and the E. coli prokaryotic expression system, to compare the immune effects of the subunit vaccines prepared in these two different expression systems. Subsequently, the immune effects of this triple conjugate immunogen were evaluated in mice. 


\section{MATERIALS AND METHODS}

\section{Strains and Plasmids}

B. melitensis $16 \mathrm{M}$ strain and B. melitensis M5 vaccine were purchased from the China Institute of Veterinary Drug Control (Beijing, China). P. pastoris GS115 and plasmid pPIC9 were purchased from Invitrogen (Carlsbad, CA, USA). E. coli DH5 $\alpha$ and pET-28a $(+)$ vector were preserved in our laboratory. The secondary antibodies were purchased from Abcam (Shanghai, China). All media were prepared according to Pichia and E. coli expressions manuals. The protection experiment was conducted in a biosafety level 3 (BSL-3) laboratory.

\section{Construction of the Recombinant Expression Vector}

The gene sequences of Omp 10 (GenBank accession number: KF780864.1), Omp 28 (GenBank accession number: JF918758.1), L7/L12 (GenBank accession number: EF173477.1) of Brucella strains were retrieved from NCBI, and BamH I, Xhol I (E. coli) and Xhol I, Not I (P. pastoris) were used, respectively, in the two expression systems. The designed Omp10-Omp28L7/L12 fusion gene sequence (1,623 bp) was synthesized after codon optimization from GENEWIZ, with the Omp10, Omp28, and L7/L12 genes being 375, 751, and 387 bp, respectively. Thus, primers for Omp10, Omp28, and L7/L12 were designed (Tables S1, S2). In addition, we predicted the three-dimensional structure of the fusion protein using the homology modeling method SWISS-MODEL (32-34). The expected size of the recombinant protein Omp10-Omp28-L7/L12 was $55.4 \mathrm{kDa}$. The fused gene was cloned into the pET-28a $(+)$ vector and the pPIC9 vector separately [pET-28a (+)-Omp10-Omp28L7/L12 and pPIC9-Omp10-Omp28-L7/L12] and confirmed by sequencing (TSINGKE, Beijing). The recombinant plasmids were transformed into E. coli $\mathrm{DH} 5 \alpha$ strain to expand the yield.

\section{Construction, Expression, Purification, and Identification of the Recombinant Proteins}

The fused Omp10-Omp28-L7/L12 fragment was first artificially synthesized after codon optimization. The PCR product was cloned into the prokaryotic expression vector pET-28a $(+)$. The constructed recombinant plasmids were verified by sequencing and then transformed into competent E. coli BL21 (DE3) to obtain the pET-28a (+)-Omp10-Omp28-L7/L12, pET-28a (+)Omp10, pET-28a (+)-Omp28, and pET-28a (+)-L7/L12 E. coli transformants. Induction was performed using $1.0 \mathrm{mmol} / \mathrm{L}$ IPTG at different times and the inclusion bodies were extracted via sonication. The transformants were cultured with IPTG while shaking at $37^{\circ} \mathrm{C}$ for $6 \mathrm{~h}$. The bacterial suspensions were centrifuged at $4^{\circ} \mathrm{C}$ and the bacterial lysates were collected at 1 , 3,5 , and $6 \mathrm{~h}$ after IPTG induction.

Meanwhile, the PCR product was cloned into the eukaryotic expression vector pPIC9. The constructed recombinant plasmid pPIC9-Omp10-Omp28-L7/L12 was verified by sequencing and then transformed into competent $P$. pastoris GS115 to obtain the transformants. The blank plasmid pPIC9 was transformed into $P$. pastoris as a negative control. Methanol was used to induce protein expression. After inducing methanol for $24,48,72$, and $96 \mathrm{~h}$, centrifuged and collected the culture supernatant.

Recombinant proteins were purified using the ProteinIso ${ }^{\mathrm{TM}}$ Ni-NTA Resin kit (TRANS, Beijing, China) and identified by SDS-PAGE and western blot analysis in accordance with a previous study. Five percentage of concentration gel and 12\% of separation gel were chosen to SDS-PAGE identification. Determined protein concentration using the Easy II Protein Quantitative Kit (BCA) (TRANS, Beijing, China).

For SDS-PAGE and western blot analysis, mouse polyclonal antibodies were prepared by multiple immunizations with the Omp10, Omp28, and L7/12 proteins separately expressed in the E. coli prokaryotic expression system. We used LE Buffer $\left(100 \mathrm{mM} \mathrm{Na} \mathrm{HPO}_{4}, 10 \mathrm{mM}\right.$ Tris-CI, $8 \mathrm{M}$ urea) to dissolve the inclusion bodies. Then the expressed recombinant Omp10-Omp28-L7/L12 proteins within the two expression systems were identified by western blot using mouse antiHis tag antibody, mouse anti-Omp10 polyclonal antibody, mouse anti-Omp28 polyclonal antibody, and mouse anti-L7/L12 polyclonal antibody.

\section{Preparation of the Vaccines}

We added $10 \%$ glycerin, $3 \%$ sucrose, and $3 \%$ sorbitol to the expressed recombinant Omp10-Omp28-L7/L12 proteins as protective agents. TPPPS has been proven to be an effective adjuvant for improving the immune effects of vaccines (35-38) and was preserved in our laboratory. TPPPS has been confirmed to elicit better humoral and cellular immunity and enhance the stimulation ability of the vaccines $(39,40)$. Moreover, TPPPS has been shown to be an effective adjuvant for promoting immune responses and improving the immune system (35, $37,41,42)$. The purified recombinant Omp10-Omp28-L7/L12 proteins were mixed with a dose of $50 \mathrm{mg} / \mathrm{mL}$ TPPPS at a ratio of $1: 1$ to a final concentration of $1 \mathrm{mg} / \mathrm{mL}$. Stability and sterility tests were then conducted to evaluate the recombinant subunit vaccines.

\section{Animal Experiments}

The total of 270 5-6 weeks old pathogen-free (SPF) BALB/c female mice, were randomly divided into nine groups (groups IIX) of 30 individuals and reared under identical environmental conditions. Ambient conditions were set at $22-25^{\circ} \mathrm{C}$ and $32-$ $42 \%$ relative humidity and the air entering the isolators was filtered. Group I mice were vaccinated with $0.1 \mathrm{mg}$ of pure Omp10-Omp28-L7/L12 (P. pastoris) subunit vaccine (Group I), group II mice were vaccinated with $0.1 \mathrm{mg}$ of TPPPS adjuvant Omp10-Omp28-L7/L12 (P. pastoris) subunit vaccine (Group II), group III mice were vaccinated with $0.1 \mathrm{mg}$ of pure Omp10Omp28-L7/L12 (E. coli) subunit vaccine (Group III), group IV mice were vaccinated with $0.1 \mathrm{mg}$ of phosphate buffered saline (PBS) (Group IV), group V mice were vaccinated with $0.1 \mathrm{mg}$ of pure Omp10 subunit vaccine (Group V), group VI mice were vaccinated with $0.1 \mathrm{mg}$ of pure Omp28 subunit vaccine (Group VI), group VII mice were vaccinated with $0.1 \mathrm{mg}$ of pure L7/L12 subunit vaccine (Group VII), group VIII mice were vaccinated with $0.1 \mathrm{mg}$ of TPPPS adjuvant Omp10-Omp28-L7/L12 (E. coli) subunit vaccine (Group VIII), group IX mice were vaccinated 
with $0.1 \mathrm{mg}$ of $B$. melitensis M5 live vaccine (Group IX) and then revaccinated at 7 and 14 days post-vaccination (dpv). At 0,14 , 28,42 , and $56 \mathrm{dpv}$, five mice per group were randomly selected to assess the relevant immune indexes. Mice were starved for $12 \mathrm{~h}$ before sampling. All mice were vaccinated by hypodermic route.

\section{Detection of Serum Antibody Levels and Cytokine Concentrations}

To determine serum reactivity against Omp10, Omp28, L7L12, and Omp10-Omp28-L7/L12, immune serum IgG, IgG1, and IgG2a levels were detected using indirect enzyme-linked immunosorbent assay (ELISA). The high binding 96 WellSingle-Break Strip Plates were coated with purified proteins $(10 \mu \mathrm{g} / \mathrm{ml})$ at $100 \mu \mathrm{l} /$ well-overnight at $4^{\circ} \mathrm{C}$. Horseradish peroxidase conjugated goat anti-mouse IgG, IgG1, or IgG2a antibodies were used to measure. Five mice serum samples were randomly sampled from each group at different times from mice orbit. The absorbance at $450 \mathrm{~nm}\left(\mathrm{OD}_{450}\right)$ of each well was detected at $30 \mathrm{~min}$ after substrate addition. The secretion of IL2 , IL-4, and IFN- $\gamma$ cytokines were tested using mouse IL-2, IL4 , and IFN- $\gamma$ ELISA kits (Langdon Bio-technology Co. Ltd., Shanghai), with the optical density at $450 \mathrm{~nm}$ were measured using a microplate reader.

\section{Proliferation of Peripheral Blood Lymphocytes}

Randomly collected fresh anticoagulated peripheral blood samples from five mice $(1.0 \mathrm{~mL} /$ mouse $)$ in each group at different times from mice orbit and mixed with $1.0 \mathrm{~mL}$ RPMI-1640. Then added $2.0 \mathrm{~mL}$ of the mixture to $5.0 \mathrm{~mL}$ of lymphocyte isolation medium (Solarbio, China) to isolate the lymphocytes (43). Centrifuged at $4^{\circ} \mathrm{C}$ for $20 \mathrm{~min}$ at $1,500 \mathrm{rpm}$ to separate the lymphocytes in the middle layer of milky white floc and collected them. Then washed them with lymphocyte washing solution twice. Proliferation of the lymphocytes was detected by the MTT method described in previous studies (44). Adjusted the density of lymphocytes to $1 \times 10^{6} / \mathrm{mL}$. In order to avoid edge effects, 1,640 cell culture solutions were added to the edge of the 96-wellplate before adding to the 96-well-plate. Subsequently, $100 \mu \mathrm{L}$ of the adjusted lymphocyte suspensions were added to every well of a 96-well cell culture plate, and each sample was repeated 6 wells. In addition, added ConA solutions to the first 3 wells to a final concentration of $5 \mu \mathrm{g} / \mathrm{mL}$, and then added an equal volume of 1,640 medium to the last 3 wells as a control. After sealing and labeling the 96-well-plate, we placed it in an incubator and kept it for $12 \mathrm{~h}$. Observed cell growth status. After the bottom of the cell culture plate was covered with cells, added $10 \mu \mathrm{L}$ MTT to each well to make the final MTT concentration reach $5 \mathrm{mg} / \mathrm{mL}$, incubated for $4 \mathrm{~h}$, discarded the culture medium, and added 100 $\mu \mathrm{L}$ DMSO to each well. After mixing, the OD value at $490 \mathrm{~nm}$ was detected using a microplate reader.

Lymphocyte transformaton rate $(\mathrm{LTR})=$ (mean of Con $\mathrm{A}$ stimulation group-mean of non-Con A stimulation group)/mean of non-Con A stimulation group.

\section{Measurement of $\mathrm{CD}^{+}$and $\mathrm{CD}^{+}{ }^{+}$ Lymphocytes Counts in Peripheral Blood}

Randomly collected fresh anticoagulated peripheral blood samples from five mice $(1.0 \mathrm{~mL} /$ mouse $)$ in each group at different times from mice orbit and mixed with $1.0 \mathrm{~mL}$ PBS. Then added $2.0 \mathrm{~mL}$ of the mixture to $5.0 \mathrm{~mL}$ of lymphocyte isolation medium (Solarbio, China). The mixture was centrifuged and lymphocytes were separated and isolated. Centrifuged at $4^{\circ} \mathrm{C}$ for $20 \mathrm{~min}$ at $1,500 \mathrm{rpm}$ to separate the lymphocytes in the middle layer of milky white floc and collect them. Then washed them with lymphocyte washing solution twice. Then added the FITC antimouse $\mathrm{CD}^{+}$and APC anti-mouse $\mathrm{CD}^{+}$dyes to samples to be tested, and placed them in a $4^{\circ} \mathrm{C}$ refrigerator for $20 \mathrm{~min}$ after taking measures to prevent light. Measured the percentages of $\mathrm{CD}^{+}{ }^{+}$and $\mathrm{CD} 8^{+} \mathrm{T}$ lymphocytes using flow cytometry (Guava Easy Cyte Mini, USA) (45).

\section{Protection Experiments}

To evaluate the protective effects of the subunit vaccines against $B$. melitensis challenge, five mice per group were challenged intraperitoneally (i.p.) with $5 \times 10^{5} \mathrm{CFU}$ of $B$. melitensis $16 \mathrm{M}$ strain in $100 \mu \mathrm{L}$ of PBS, 4 weeks after the last immunization. Notably, a positive control group was added with another five mice that were vaccinated intraperitoneally with $5 \times 10^{4} \mathrm{CFU}$ of $B$. melitensis M5 live vaccine 4 weeks before the challenge. Mice were euthanized at 4 weeks post-challenge and their spleens were removed aseptically. Determine the number of $B$. melitensis (CFU) in each spleen, and express the results as the mean $\log _{10}$ $\mathrm{CFU} \pm$ standard deviation (SD) of each group. The log unit of protection was obtained by subtracting the mean $\log _{10} \mathrm{CFU}$ of the vaccinated group from the mean $\log _{10}$ CFU of the PBS control group.

\section{Statistical Analyses}

Data were expressed as mean \pm standard deviation. Duncan's multiple-range test was performed to analyze differences among groups using SPSS 17.0. Values of $P<0.05$ were considered statistically significant.

\section{RESULTS}

\section{Construction, Expression, and Identification of Recombinant Proteins}

Cloned the Omp10-Omp28-L7/L12 fusion gene correctly into the eukaryotic expression vector pPIC9 after sequencing identification. After induced with methanol, using SDS-PAGE, we observed $55.4 \mathrm{kDa}$ protein bands in the culture supernatant of recombinant pPIC9-Omp10-Omp28-L7/L12 transformants at different times (Figure 1A, left). After $72 \mathrm{~h}$ of culture, protein was measured in the supernatant and the highest protein concentration $(9.4 \mathrm{mg} / \mathrm{L})$ was observed at $96 \mathrm{~h}$. Meanwhile, cloned the Omp10-Omp28-L7/L12 fusion gene correctly into the prokaryotic expression vector pET-28a $(+)$ after sequencing identification. SDS-PAGE showed that the recombinant $\mathrm{pET}-28 \mathrm{a}$ (+)-Omp10-Omp28-L7/L12 transformants corresponded to the expressed protein bands of $55.4 \mathrm{kDa}$ (Figure 1A, right). The peak protein concentration $(7.2 \mathrm{mg} / \mathrm{L})$ occurred at $6 \mathrm{~h}$. 


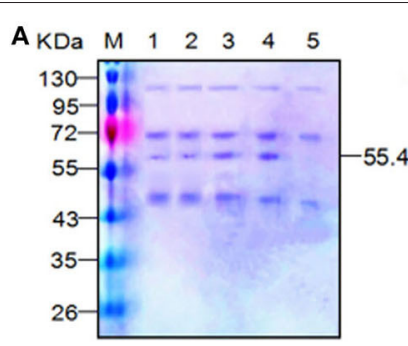

c
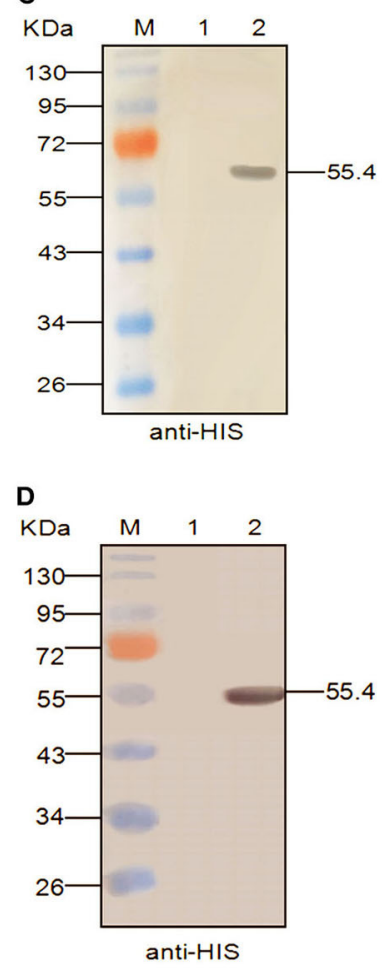
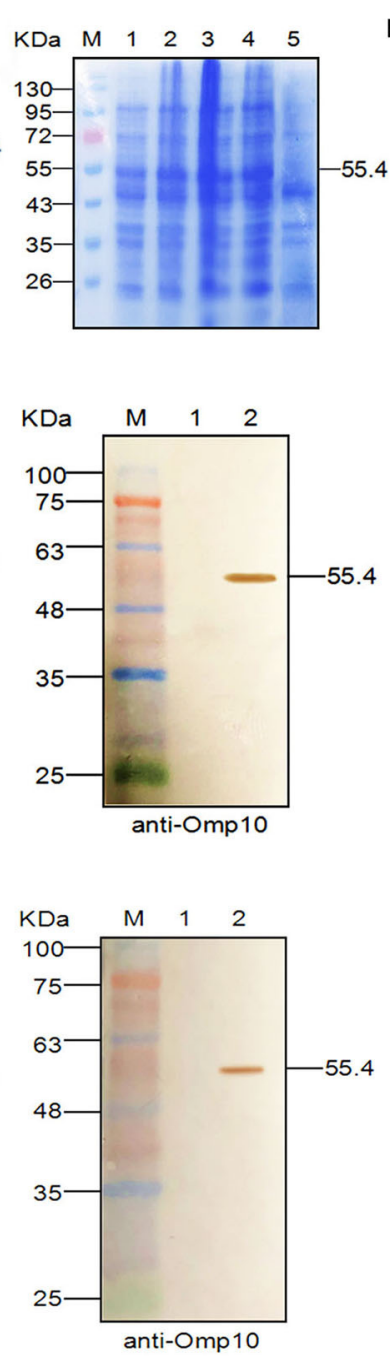
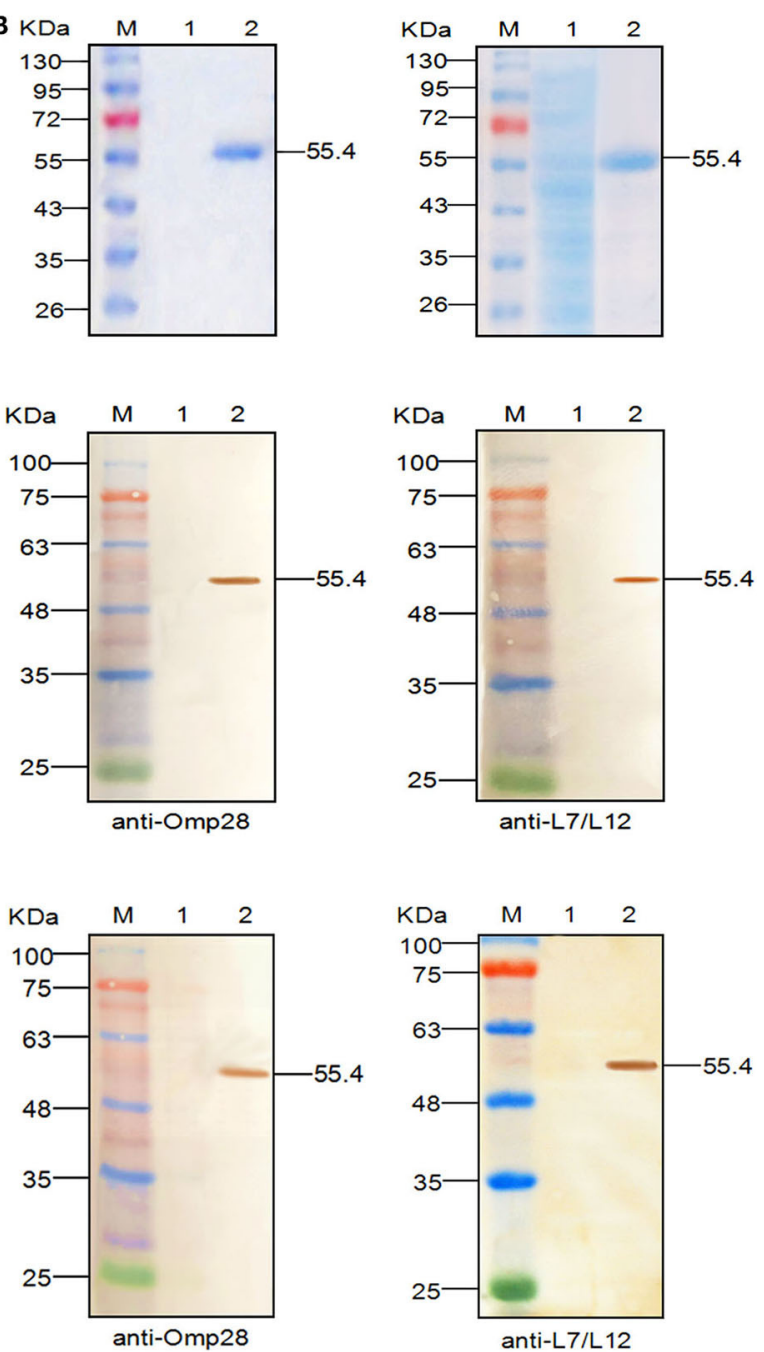

anti-L7/L12

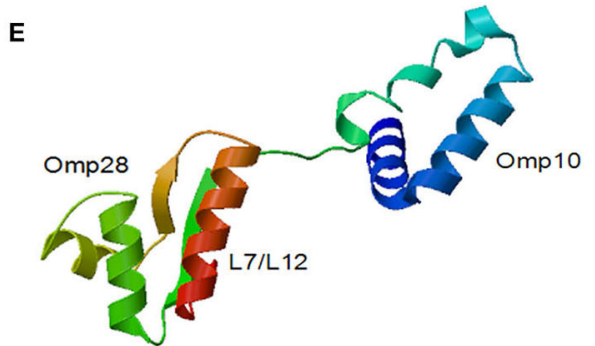

FIGURE 1 | Expression, SDS-PAGE identification, and western blot analysis of the recombinant proteins. (A) SDS-PAGE identification of the recombinant Omp10-Omp28-L7/L12 protein $(55.4 \mathrm{kDa})$ at different induction times. Left: M, Page ruler pre-stained protein ladder; lanes 1-4, culture supernatant of $P$. pastoris transformed with the recombinant plasmids after $24,48,72$, and $96 \mathrm{~h}$ of methanol induction; lane 5 , culture supernatant of $P$. pastoris transformed with blank pPIC9 vector (negative control). Right: M, Page ruler pre-stained protein ladder; lanes 1-4, expression products of $E$. coli BL21 (DE3) transformed with recombinant plasmids after 1, 3, 5, and 6 h of IPTG induction; lane 5, expression product of E. coli BL21 (DE3) transformed with blank pET28a (+) vector (negative control). (B) Purification of the fused Omp10-Omp28-L7/L12 protein (55.4 kDa). Left: M, Page ruler pre-stained protein ladder; lane 1, culture supernatant after column chromatography; lane 2, purified Omp10-Omp28-L7/L12 protein (P. pastoris). Right: M, Page ruler pre-stained protein ladder; lane 1, unpurified protein product; lane 2, purified Omp10-Omp28-L7/L12 protein (E. coli). (C) Western blot identification of the recombinant proteins (55.4 kDa) using anti-His tag antibody, mouse anti-Omp10 polyclonal antibody, mouse anti-Omp28 polyclonal antibody, and mouse anti-L7/L12 polyclonal antibody. M, protein molecular size page ruler; lane 1, culture supernatant of $P$. pastoris transformed with blank pPIC9 vector (negative control); lane 2, culture supernatant of $P$. pastoris transformed with the recombinant plasmids at $96 \mathrm{~h}$ post-induction. (D) Western blot identification of the recombinant proteins ( $55.4 \mathrm{kDa})$ using anti-His tag antibody, mouse anti-Omp10 polyclonal antibody, mouse anti-Omp28 polyclonal antibody, and mouse anti-L7/L12 polyclonal antibody. M, protein molecular size page ruler; lane 1, expression products of $E$. coli BL21 (DE3) transformed with blank pET28a (+) vector (negative control); lane 2, expression products of E. coli BL21 (DE3) transformed with the recombinant plasmids at $6 \mathrm{~h}$ post-induction. (E) Predicted 3D structure of the recombinant protein. 

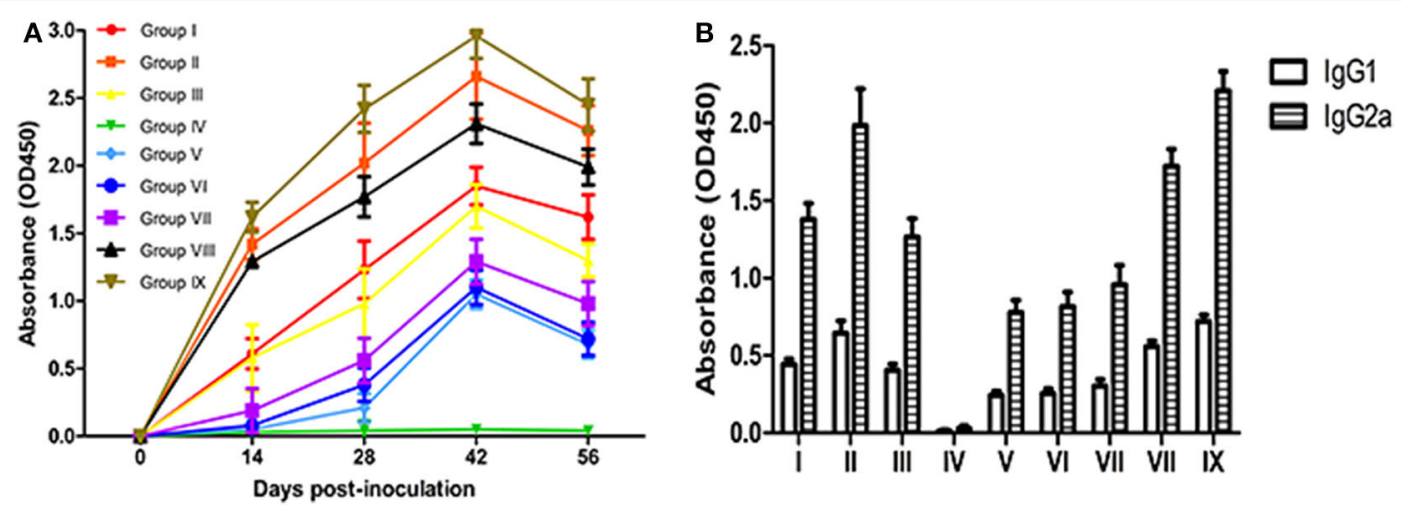

FIGURE 2 | Changes in serum antibody levels in mice. Mice from the nine groups were vaccinated with pure Omp10-Omp28-L7/L12 (P. pastoris) subunit vaccine (Group I), TPPPS adjuvant Omp10-Omp28-L7/L12 (P. pastoris) subunit vaccine (Group II), pure Omp10-Omp28-L7/L12 (E. coli) subunit vaccine (Group III), PBS (Group IV), pure Omp10 subunit vaccine (Group V), pure Omp28 subunit vaccine (Group VI), pure L7/L12 subunit vaccine (Group VII), TPPPS adjuvant Omp10-Omp28-L7/L12 (E. coli) subunit vaccine (Group VIII), or B. melitensis M5 live vaccine (Group IX) at 5-6 weeks old. Serums were collected at 0, 14, 28, 42, and 56 dpv. (A) The IgG was then determined using indirect ELISA. (B) Specific antibody IgG1 and IgG2a levels were measured by ELISA in sera obtained at 45 days after the first immunization. All values shown are means \pm SD from five independent experiments.

Single-protein bands with a molecular weight of $55.4 \mathrm{kDa}$ were also detected in the SDS-PAGE results after purification (Figure 1B). After western blot analysis, we observed that the single reaction bands $(55.4 \mathrm{kDa})$ corresponded to the bands in the SDS-PAGE, indicating the expression of the recombinant Omp10-Omp28-L7/L12 proteins and their specific reactivity to several specific antibodies mentioned above (Figures 1C,D). In addition, we obtained the three-dimensional structural model of the fusion protein Omp10-Omp28-L7/L12 through the homology modeling function of the SWISS-MODEL website. The results showed that the folding of each protein segment maintained their individual structures by the connection of a flexible peptide (Figure 1E).

\section{Comparison of Immune Effects by Measuring Serum Antibody Levels}

In order to compare the immune effects of vaccines, it is essential to measure the level of antibodies induced by vaccines. The dynamic changes in serum antibody levels in each group are shown in Figure 2A. A higher OD value represents a higher antibody level detected with the indirect enzyme-linked immunosorbent assay. The results show that the antibody levels of vaccinated mice were significantly higher than levels in the PBS control group mice at $14-56 \mathrm{dpv}(P<0.05)$. Although the antibody levels of the live vaccine group (Group IX) were higher than all experimental groups. The difference between groups Omp10-Omp28-L7/L12 (P. pastoris) (Group I) and Omp10Omp28-L7/L12 (E. coli) (Group III) was not significant $(P>$ 0.05 ). And the antibody levels in single proteins groups were lower than fusion protein groups. In addition, the antibody levels in group Omp10-Omp28-L7/L12 + TPPPS (Group II and Group VIII) were significantly higher compared to the other vaccinated protein groups at $14-56 \mathrm{dpv}(P<0.05)$. In order to analyze the potential role of IgG subtypes in the prevention of Brucella infection, we examined the proportion of Th1-related IgG2a and Th2-related IgG1 in the total serum IgG of each group by ELISAs at 45 days after the first immunization. The specific IgG2a titers were higher than the specific IgG1 titers in all vaccinated groups indicating a shift toward a Th1 type of response (Figure 2B). Omp10 (Group V), Omp 28 (Group VI) and L7 / L12 (Group VII) groups also had higher IgG2a titers than IgG1 titers, indicating that a single protein can also shift the immune response to Th1 but with lower titers. The results showed that the recombinant Brucella protein Omp10-Omp28-L7/L12 had good immunogenicity, and TPPPS could effectively promote antibody production in mice given recombinant subunit vaccine.

\section{Comparison of Immune Effects by Measuring Cytokine Secretion}

Cytokines are important in development, maturation, differentiation, and activation of immune cells. They help to regulate the type and intensity of immune responses and are essential for the resistance of infections (46). Cytokines IL-2 and IFN- $\gamma$ play an important role in cell-mediated immune response, while IL-4 promotes antibody production and acts on humoral immune response. The serum levels of IL-2, IL-4, and IFN- $\gamma$ in all groups are displayed in Figures 3A-C. The secretion of IL-2, IL-4, and IFN- $\gamma$ in vaccinated mice increased significantly compared with the PBS control group, reaching peak values at $42 \mathrm{dpv}(P<0.05)$. Although the contents of IL-2, IL-4, and IFN- $\gamma$ of live vaccine group (Group IX) were higher than all experimental groups. The contents of IL-2, IL-4, and IFN- $\gamma$ in the Omp10-Omp28-L7/L12 + TPPPS group (Group II and Group VIII) were significantly higher than those in Omp10-Omp28-L7/L12 (P. pastoris) group (Group I) and Omp10-Omp28-L7/L12 (E. coli) group (Group III) $(P<0.05)$. The TPPPS adjuvant group showed higher contents of IL-2, IL-4, and IFN- $\gamma$ than the other groups at $14-56 \mathrm{dpv}(P<0.05)$. And the contents of IL-2, IL-4, and IFN- $\gamma$ in single proteins groups were lower than fusion protein groups. These results indicate that TPPPS could significantly promote the productions of IL-2, IL- 4 , and IFN- $\gamma$ in vaccinated mice. 

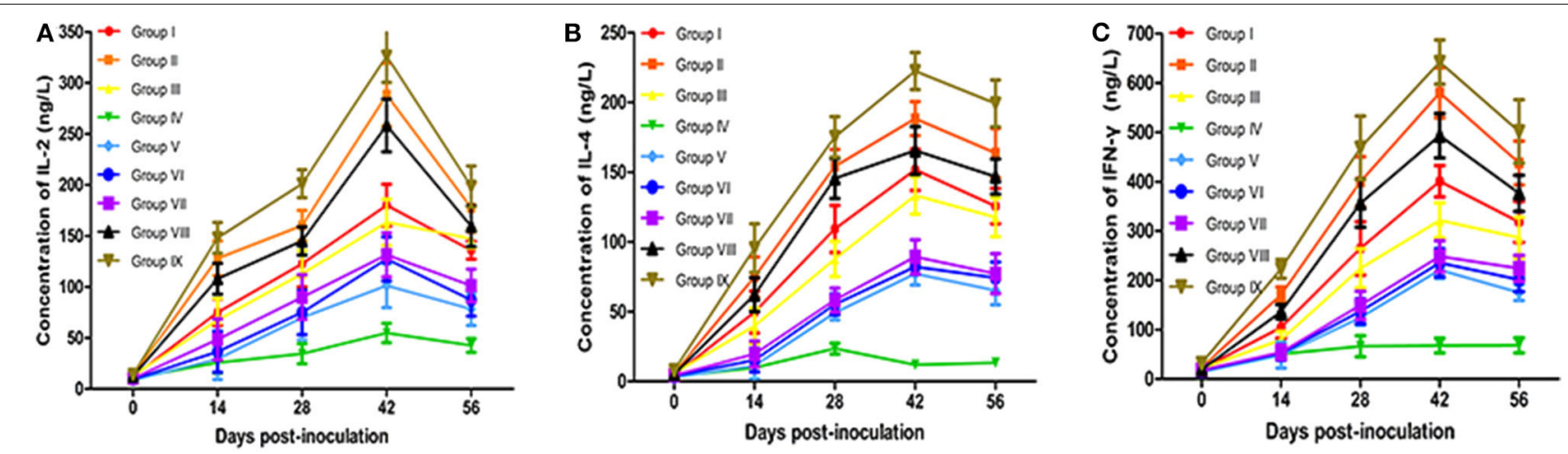

FIGURE 3 | Changes in cytokines in mice. Mice from the nine groups were vaccinated with pure Omp10-Omp28-L7/L12 (P. pastoris) subunit vaccine (Group I), TPPPS adjuvant Omp10-Omp28-L7/L12 (P. pastoris) subunit vaccine (Group II), pure Omp10-Omp28-L7/L12 (E. coli) subunit vaccine (Group III), PBS (Group IV), pure Omp10 subunit vaccine (Group V), pure Omp28 subunit vaccine (Group VI), pure L7/L12 subunit vaccine (Group VII), TPPPS adjuvant Omp10-Omp28-L7/L12 (E. coli) subunit vaccine (Group VIII), or B. melitensis M5 live vaccine (Group IX) at 5-6 weeks old. Serums were collected at 0, 14, 28, 42, and 56 dpv. Secretion of IL-2 (A), IL-4 (B), and IFN- $\gamma$ (C) was detected using mouse IL-2, IL-4, and IFN- $\gamma$ ELISA kits. All values shown are means \pm SD from five independent experiments.

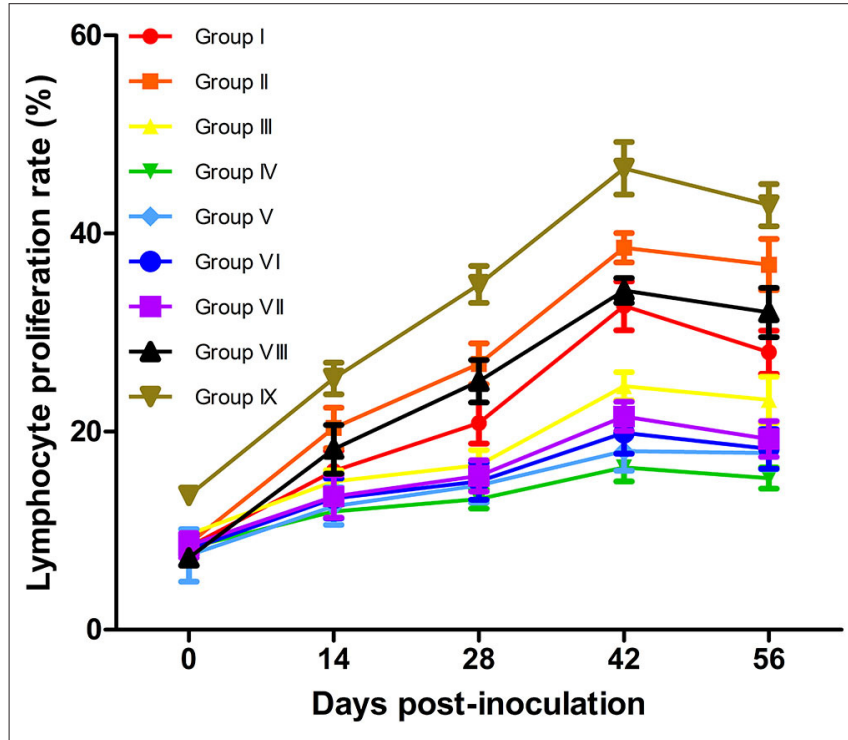

FIGURE 4 | Changes in T lymphocyte proliferation ratio in mice. Mice from the nine groups were vaccinated with pure Omp10-Omp28-L7/L12 (P. pastoris) subunit vaccine (Group I), TPPPS adjuvant Omp10-Omp28-L7/L12 (P. pastoris) subunit vaccine (Group II), pure Omp10-Omp28-L7/L12 (E. coli) subunit vaccine (Group III), PBS (Group IV), pure Omp10 subunit vaccine (Group V), pure Omp28 subunit vaccine (Group VI), pure L7/L12 subunit vaccine (Group VII), TPPPS adjuvant Omp10-Omp28-L7/L12 (E. coli) subunit vaccine (Group VIII), or B. melitensis M5 live vaccine (Group IX) at 5-6 weeks old. Peripheral blood was collected from each animal at $0,14,28,42$, and 56 $\mathrm{dpv}$. The ratio of $\mathrm{T}$ lymphocyte proliferation in the same column was compared using Duncan's multiple-range tests. All values shown are means \pm SD from five independent experiments.

\section{Comparison of Immune Effects by Measuring Lymphocyte Proliferation}

Proliferation ratios are commonly used to assess cellular immunity (47). The results of lymphocyte proliferation rates are shown in Figure 4. At 14-56 dpv, lymphocyte transformation rates (LTRs) in vaccinated mice were significantly higher than those in the PBS-treated (Group IV) mice $(P<0.05)$. Although the LTRs of live vaccine group (Group IX) were higher than all experimental groups. Notably, the LTRs in the Omp10-Omp28L7/L12 ( $P$. pastoris) (Group I) mice were higher than those in the Omp10-Omp28-L7/L12 (E. coli) (Group III) mice, but the difference was not significant $(P>0.05)$. Furthermore, the Omp10-Omp28-L7/L12 + TPPPS (Group II and Group VIII) mice showed significantly higher LTRs than the Omp10-Omp28L7/L12 (P. pastoris) (Group I) and the Omp10-Omp28-L7/L12 (E. coli) (Group III) mice at $14-56 \mathrm{dpv}(P<0.05)$. And the LTRs in single protein groups were lower than fusion protein groups. These results suggest that TPPPS significantly promotes cellular and humoral immune responses, induced by the Omp10Omp28-L7/L12 antigen.

\section{Comparison of Immune Effects by Measuring Lymphocyte Subset Ratios}

The levels of $\mathrm{CD}^{+}$and $\mathrm{CD} 8^{+} \mathrm{T}$ lymphocytes directly reflect the immune function of animals and are the clearest indicators of immune system damage in infected animals (48). The changes in $\mathrm{CD}^{+}$and $\mathrm{CD}^{+} \mathrm{T}$ lymphocyte counts in peripheral blood are shown in Tables 1, 2, respectively. Although the levels of $\mathrm{CD}^{+}$and $\mathrm{CD}^{+}{ }^{+} \mathrm{T}$ lymphocytes of live vaccine group (Group IX) were higher than all experimental groups. The levels of $\mathrm{CD} 4^{+}$ and $\mathrm{CD} 8^{+} \mathrm{T}$ lymphocytes in vaccinated mice were significantly higher than those in the PBS-treated (Group IV) mice at 14-56 $\mathrm{dpv}(P<0.05)$. The levels of $\mathrm{CD}^{+}$and $\mathrm{CD} 8^{+} \mathrm{T}$ lymphocytes in Omp10-Omp28-L7/L12 (P. pastoris) (Group I) mice were higher than those in Omp10-Omp28-L7/L12 (E. coli) (Group III) mice, but the difference was not significant $(P>0.05)$. Furthermore, the percentages of $\mathrm{CD}^{+}$and $\mathrm{CD}^{+} \mathrm{T}$ lymphocytes in Omp10Omp28-L7/L12 + TPPPS (Group II and Group VIII) mice were significantly higher than those in the Omp10-Omp28-L7/L12 (P. pastoris) (Group I) and the Omp10-Omp28-L7/L12 (E. coli) (Group III) mice at $14-56 \mathrm{dpv}(P<0.05)$. And the levels of $\mathrm{CD}^{+}$and $\mathrm{CD}{ }^{+} \mathrm{T}$ lymphocytes in single proteins groups were 
TABLE 1 | Changes in CD4 ${ }^{+} \mathrm{T}$ lymphocyte counts in the peripheral blood.

\begin{tabular}{|c|c|c|c|c|c|}
\hline \multirow[t]{2}{*}{ Group $^{A}$} & \multicolumn{5}{|c|}{ Days post-vaccination ${ }^{B}$} \\
\hline & 0 & 14 & 28 & 42 & 56 \\
\hline I & $9.69 \pm 0.53^{a}$ & $15.74 \pm 1.28^{b}$ & $22.87 \pm 2.86^{b, c}$ & $30.28 \pm 4.07^{c}$ & $23.88 \pm 1.95^{\mathrm{C}}$ \\
\hline ॥ & $8.63 \pm 1.25^{\mathrm{a}}$ & $20.54 \pm 2.85^{c}$ & $29.34 \pm 3.44^{d}$ & $38.03 \pm 1.61^{d}$ & $32.49 \pm 2.69^{d}$ \\
\hline III & $9.81 \pm 0.80^{a}$ & $15.33 \pm 0.69^{b}$ & $19.54 \pm 1.73^{b}$ & $27.06 \pm 2.11^{c}$ & $18.97 \pm 1.75^{\mathrm{C}}$ \\
\hline IV & $8.61 \pm 1.33^{a}$ & $9.88 \pm 1.01^{\mathrm{a}}$ & $10.70 \pm 1.16^{\mathrm{a}}$ & $11.02 \pm 1.29^{a}$ & $11.43 \pm 0.85^{\mathrm{a}}$ \\
\hline V & $9.26 \pm 0.88^{a}$ & $10.72 \pm 0.68^{a}$ & $12.41 \pm 1.89^{a}$ & $18.82 \pm 2.96^{b}$ & $13.01 \pm 1.74^{b}$ \\
\hline VI & $9.24 \pm 0.33^{a}$ & $11.70 \pm 1.25^{\mathrm{a}}$ & $13.39 \pm 1.65^{\mathrm{a}}$ & $19.80 \pm 2.21^{b}$ & $13.99 \pm 1.85^{b}$ \\
\hline VII & $9.56 \pm 1.33^{a}$ & $13.02 \pm 0.98^{\mathrm{ab}}$ & $14.71 \pm 1.27^{a}$ & $21.12 \pm 1.75^{b}$ & $15.31 \pm 1.08^{b}$ \\
\hline VIII & $9.74 \pm 0.95^{a}$ & $20.13 \pm 3.09^{c}$ & $26.02 \pm 2.21^{\mathrm{cd}}$ & $34.81 \pm 1.48^{d}$ & $27.58 \pm 2.50^{d}$ \\
\hline IX & $9.85 \pm 0.54^{a}$ & $21.40 \pm 3.66^{c}$ & $36.00 \pm 1.82^{\mathrm{e}}$ & $47.54 \pm 0.72^{\mathrm{e}}$ & $38.40 \pm 1.99^{e}$ \\
\hline
\end{tabular}

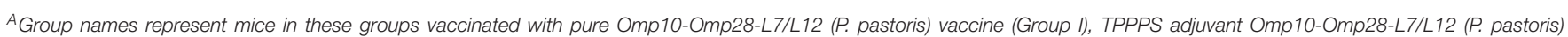

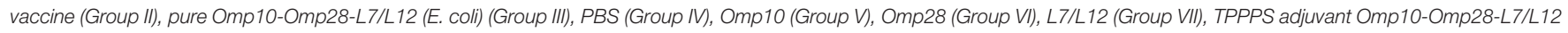
(E. coli) (Group VIII) or B. melitensis M5 (Group IX) at 5-6 weeks old.

${ }^{B} \mathrm{CD} 4+$ Tlymphocyte counts in the same column were compared using Duncan's multiple-range tests. Different superscript lowercase letters indicate significant differences $(P<0.05)$. Data are expressed as mean percentage $\pm S D$.

TABLE 2 | Changes in CD8 ${ }^{+}$T lymphocyte counts in the peripheral blood.

\begin{tabular}{|c|c|c|c|c|c|}
\hline Group $^{A}$ & \multicolumn{5}{|c|}{ Days post-vaccination ${ }^{B}$} \\
\hline$\|$ & $5.53 \pm 0.81^{\mathrm{a}}$ & $13.78 \pm 2.47^{e}$ & $17.47 \pm 1.45^{\mathrm{d}}$ & $21.61 \pm 0.91^{\mathrm{e}}$ & $18.57 \pm 2.18^{f}$ \\
\hline III & $5.87 \pm 0.48^{a, b}$ & $9.00 \pm 0.46^{\mathrm{b}, \mathrm{c}}$ & $10.20 \pm 0.94^{b}$ & $15.38 \pm 1.20^{d}$ & $12.37 \pm 1.10^{\mathrm{c}, \mathrm{d}}$ \\
\hline IV & $5.94 \pm 0.92^{a, b}$ & $6.15 \pm 0.90^{a}$ & $6.14 \pm 0.45^{a}$ & $6.26 \pm 0.73^{a}$ & $6.77 \pm 0.73^{a}$ \\
\hline VII & $6.80 \pm 0.21^{\mathrm{a}, \mathrm{b}, \mathrm{c}}$ & $8.44 \pm 0.39^{a, b, c}$ & $9.63 \pm 0.51^{\mathrm{b}}$ & $13.21 \pm 1.03^{\mathrm{c}}$ & $10.81 \pm 1.34^{b, c}$ \\
\hline VIII & $7.19 \pm 0.55^{c}$ & $12.15 \pm 1.76^{\mathrm{d}, \mathrm{e}}$ & $14.83 \pm 1.34^{c}$ & $19.78 \pm 0.84^{e}$ & $16.47 \pm 1.41^{e, f}$ \\
\hline IX & $8.54 \pm 1.13^{d}$ & $18.42 \pm 2.35^{\dagger}$ & $21.44 \pm 2.12^{\mathrm{e}}$ & $28.44 \pm 1.08^{f}$ & $22.01 \pm 1.81^{g}$ \\
\hline
\end{tabular}

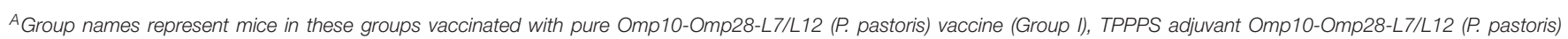

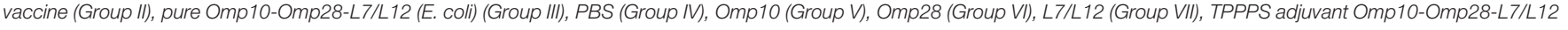
(E. coli) (Group VIII), or B. melitensis M5 (Group IX) at 5-6 weeks old.

${ }^{B} \mathrm{CD} 8^{+}$Tlymphocyte counts in the same column were compared using Duncan's multiple-range tests. Different superscript lowercase letters indicate significant differences $(P<0.05)$. Data are expressed as mean percentage $\pm S D$.

lower than fusion protein groups. These results suggest that TPPPS significantly increases the levels of CD4 ${ }^{+}$and $\mathrm{CD} 8^{+} \mathrm{T}$ lymphocytes in the peripheral blood of vaccinated mice.

\section{Protective Effects of Brucella Subunit Vaccines}

In this experiment, the number of bacteria in the spleen of the immunized mice was significantly reduced compared to the mice inoculated with PBS, and the vaccine efficacy was expressed as the $\log _{10}$ of protection. As shown in Table 3, the immunity-induced protection levels of all tested vaccines were significantly higher compared to the PBS control group $(P<$ 0.05). The recombinant Omp10-Omp28-L7/L12 (P. pastoris) protein induced a level of protection 1.49 logs against the challenge, whereas the recombinant Omp10-Omp28-L7/L12 (E. coli) protein induced a level of protection 0.98 logs against the challenge, with no significant difference between the two groups. Among the test vaccines, the level of protection (2.41 logs) in Omp10-Omp28-L7/L12 + TPPPS (Group II and Group VIII) was significantly higher than that in the other protein groups $(P<0.05)$. And the levels of protection in single protein groups were lower than fusion protein groups. However, we also noticed that all of the evaluated subunit vaccines induced lower protective levels than the $B$. melitensis M5 live vaccine (2.73 logs), especially the subunit vaccines without TPPPS, which had significantly lower levels of protection than the $B$. melitensis M5 vaccine $(P<0.05)$. These data demonstrate that the expressed Omp10-Omp28-L7/L12 proteins effectively protected mice against Brucella infection, and using TPPPS as an adjuvant can significantly enhance the protection of Omp10-Omp28-L7/L12 subunit vaccines against Brucella infection. 
TABLE 3 | Protection against challenge with B. melitensis $16 \mathrm{M}$ after immunization with various vaccines.

\begin{tabular}{lcc}
\hline Vaccine & $\begin{array}{c}\text { Log }_{10} \text { CFU/spleen } \\
\text { (mean } \pm \text { SD) }\end{array}$ & $\begin{array}{c}\text { Log } \\
\text { protection }\end{array}$ \\
\hline B. melitensis M5 & $2.12 \pm 0.17^{\mathrm{c}}$ & 2.73 \\
Omp10-Omp28-L7/L12 (P. pastoris) & $3.36 \pm 0.32^{\mathrm{b}}$ & 1.49 \\
Omp10-Omp28-L7/L12 (P. pastoris) + TPPPS & $2.44 \pm 0.54^{\mathrm{c}}$ & 2.41 \\
Omp10-Omp28-L7/L12 (E. coli) & $3.87 \pm 0.55^{\mathrm{b}}$ & 0.98 \\
PBS & $4.85 \pm 0.45^{\mathrm{a}}$ & 0.00 \\
Omp10 & $4.45 \pm 0.83^{\mathrm{b}}$ & 0.40 \\
Omp28 & $4.28 \pm 0.89^{\mathrm{b}}$ & 0.57 \\
L7/L12 & $4.16 \pm 0.47^{\mathrm{b}}$ & 0.69 \\
Omp10-Omp28-L7/L12 (E. coli) + TPPPS & $2.97 \pm 0.68^{\mathrm{c}}$ & 1.88 \\
\hline
\end{tabular}

Different superscript lowercase letters indicate significant differences among different groups of mice ( $P<0.05$ estimated using Duncan's multiple-range tests).

\section{DISCUSSION}

Brucella still poses a significant threat to domestic animals and humans in many countries. At present, the use of live Brucella vaccines is limited, so improving the immunization strategy of Brucella subunit vaccines is critical to prevent and control the disease. In this study, we fused three protective antigen genes of Omp10, Omp28, and L7/L12 and expressed this fused protein in both eukaryotic and prokaryotic expression systems. The results indicate that the recombinant Omp10-Omp28-L7/L12 subunit antigens induce positive immune responses and protective effects against Brucella, and the protective effects and immunogenicity of the recombinant Omp10-Omp28-L7/L12 protein expressed in the eukaryotic system have advantages compared to those of the prokaryotic Omp10-Omp28-L7/L12 recombinant protein.

Subunit vaccines usually contain one or more specific antigenic epitopes, thus, they have affirmative advantages compared to traditional live and inactivated vaccines, such as targeted immunity, improved safety, fast and easy production, low cost, etc. However, in terms of clinical protection, subunit vaccines rarely have an advantage over conventional vaccines because of their single antigen component. Therefore, the development of multivalent subunit vaccines may be an effective way to develop new generation vaccines. The recombinant expression of the fusion gene is a feasible method to increase the number of epitopes, and this can effectively avoid the repetitive work of single epitope expression and recombination. Previous studies have shown that vaccines composed of a single bacterial protein usually cannot prevent Brucella infection (49). Notably, some studies have also demonstrated that for the brucellosis vaccine, the use of compound antigens may provide better immune protection. Simborio et al. showed that the combined rOmp (rOmp10, 19, and 28) antigens have good reactivity for diagnosing disease and provide protection against $B$. abortus infection (11); Golshani et al. found that rL7/L12-TOmp31 can induce a strong IgG response compared with a single protein (25); Ghasemi et al. demonstrated that a recombinant antigen containing rOmp31 + rTF provides a high level of protection against $B$. melitensis, which makes it a good candidate for the development of a multivalent subunit vaccine (50). In view of these results, we designed a fusion protein expression system containing multiple protective antigens to prepare the Brucella subunit vaccine. Our results indicate that the recombinant Omp10-Omp28-L7/L12 protein can induce protective immune responses and protection against Brucella.

Relative to other proteins, the molecular weights of the outer membrane proteins Omp10 and Omp28 and the ribosomal protein L7/L12 of Brucella are small, which makes them convenient for tandem expression. Thus, in this study, we used these three antigenic proteins to create fusion proteins. The results of our study suggest that the antibody levels, peripheral blood lymphocyte proliferation, number of $\mathrm{CD}^{+}$and $\mathrm{CD}^{+} \mathrm{T}$ lymphocytes, and cytokine secretion produced by the Omp10-Omp28-L7/L12 recombinant protein vaccinated groups were significantly higher than those of the negative control group, indicating that recombinant protein vaccines can produce specific antibodies in mice and exert good immunogenicity. The detection of lymphocytes and the results of flow cytometry showed that the frequency of $\mathrm{CD}^{+}$and $\mathrm{CD} 8^{+} \mathrm{T}$ cells increased significantly. This result demonstrated the activation of antigenspecific $\mathrm{T}$ cells in vivo. Although the importance of these two $\mathrm{T}$ cell populations has been disputed, both $\mathrm{CD}^{+}$and $\mathrm{CD}^{+}{ }^{+} \mathrm{T}$ cells may be important in immunity against Brucella infection. $\mathrm{BALB} / \mathrm{c}$ mice were infected with Brucella and immunized with $\mathrm{CD}^{+}$and $\mathrm{CD}^{+} \mathrm{T}$ cells for 6 weeks, the CFU of Brucella in the spleen of the mice was found to be lower than that of untreated mice (51). This showed that both $\mathrm{T}$ cells play a role in the immunization of Brucella. However, recent experiments have shown that the ability of MHC I-deficient mice (without $\mathrm{CD}^{+} \mathrm{T}$ cells function) to control infection after infection with S19 was much lower than that of wild MHC II-deficient mice (without $\mathrm{CD}^{+}{ }^{+} \mathrm{T}$ cells function). The ability to control infection was similar to that of normal mice (52), indicating that $\mathrm{CD} 8^{+} \mathrm{T}$ cell plays a major role; and further experiments indicated that $\mathrm{CD}^{+} \mathrm{T}$ cells play a limited role in the early stages of infection. In addition, experiments with MHC I-deficient mice confirmed that $\mathrm{CD} 8^{+} \mathrm{T}$ cells play a major antibacterial role after the peak of infection. However, since the number of $\mathrm{CD}^{+} \mathrm{T}$ cells accounts for the vast majority of T cells, and they can also secrete IFN- $\gamma$, the ability of $\mathrm{CD}^{+}{ }^{+} \mathrm{T}$ cells to control Brucella cannot be ignored. About the critical role of Th1 and Th2 immune responses in the control of Brucella infection, the levels of Th1 cytokine (IL2 and IFN- $\gamma$ ) and Th2 cytokine (IL-4) from all mice groups were evaluated and enhanced levels of IL-2, IL-4 and IFN- $\gamma$ (P $<0.05)$ were observed in comparison to the PBS group. The result of the challenge experiment indicates that immunization of mice with Omp10-Omp28-L7/L12 subunit vaccines results in a significant reduction in the $B$. melitensis burden in the spleens of mice and has good protective effects. Taken together, the recombinant antigen of Omp10-Omp28-L7/L12 elicited a good immune response and could serve as a good candidate for the development of multivalent subunit vaccines that provide high levels of protection against Brucella. However, we also found that the protective effect of the recombinant Omp10-Omp28L7/L12 protein was not as effective as the live vaccine. Other 
previously reported recombinant proteins also showed similar results $(53,54)$, which were probably due to the lack of cellular immune response compared to the live vaccine. Considering the advantages and disadvantages of both vaccines, a differentiated Brucella immunotherapy is necessary for specific situations in different epidemic areas.

It has been revealed that TPPPS can enhance the stimulation ability of the vaccines and induce better cellular and humoral immunity $(39,40)$. TPPPS was used as an adjuvant in our research, showed an obvious enhancement in immune response and protection to the recombinant Omp10-Omp28-L7/L12. Although the live vaccine group showed better protection, the difference between the TPPPS adjuvant group and the live vaccine group was not significant. This means that the use of TPPPS as an adjuvant narrows the gap between the recombinant Omp10-Omp28-L7/L12 subunit vaccine and the live vaccine. Therefore, TPPPS can be used as a potential adjuvant for Brucella subunit vaccines.

Herein, we used $P$. pastoris eukaryotic and E. coli prokaryotic expression systems to express the recombinant Omp10-Omp28L7/L12 protein. The advantages of the E. coli expression system are easy growth and simple gene manipulation, therefore the system is considered to be the most economical, convenient and effective expression system (55). However, a broad understanding holds that E. coli lacks proper post-translational processing mechanism leads to vast differences between the expressed bacterial epitopes and its natural structure (56). The $P$. pastoris eukaryotic expression system has some advantages, such as easy culture, high yield, accurate post-translational modification, and low interference of natural proteins, etc. Additionally, this secretory expression system also facilitates subsequent protein purification (57). As expected, the recombinant Omp10Omp28-L7/L12 was secreted into the medium at a high yield, and the content of natural proteins in $P$. pastoris were very low, which greatly improved the purification efficiency of recombinant fusion protein. Moreover, both the quantity and the immunogenicity of the Omp10-Omp28-L7/L12 recombinant protein expressed in $P$. pastoris were slightly higher than those of the recombinant protein in E. coli. From the protection experiment, the recombinant Omp10-Omp28-L7/L12 protein expressed in $P$. pastoris induced a higher level of protection than the recombinant Omp10-Omp28-L7/L12 protein expressed in E. coli. And the fusion proteins induced a higher level of protection than the single proteins. Thus, given the protein expression quantity, protein purification, and immune effects, the $P$. pastoris expression system is more suitable for expressing the recombinant fusion protein than the $E$. coli expression system in our study.

\section{CONCLUSION}

P. pastoris eukaryotic and E. coli prokaryotic expression systems were used to prepare Brucella subunit vaccines in this study. We have demonstrated that recombinant antigen containing Omp10-Omp28-L7/L12 is a good candidate for the development of multivalent subunit vaccines, which provide definite protection against Brucella. We also found that the quick performance and immune effects of the recombinant Brucella subunit expressed in P. pastoris have certain advantages compared with the traditional E. coli expression system. Moreover, TPPPS performed as a good adjuvant in the subunit vaccine. Together, the results of this study reveal the potential of the fused multivalent subunit vaccine for the prevention of brucellosis.

\section{DATA AVAILABILITY STATEMENT}

The datasets presented in this study can be found in online repositories. The names of the repository/repositories and accession number(s) can be found in the article/Supplementary Material.

\section{ETHICS STATEMENT}

The animal operation procedures were approved by the Animal Care and Use Committee of Shandong Agricultural University (permit number: 20010510) and implemented according to the Guidelines for Experimental Animals of the Ministry of Science and Technology (Beijing, China).

\section{AUTHOR CONTRIBUTIONS}

RZ, KW, LH, and LZ designed the research. LZ, QW, YW, and YX performed the research. LZ, LH, KW, DP, HH, and RZ analyzed the data. LZ, LH, KW, and RZ wrote the manuscript. All authors contributed to the article and approved the submitted version.

\section{FUNDING}

This project was funded by the National Key Research and Development Program of China (2016YFD0500905), the Modern Agricultural Industry Technology System Foundation of Shandong Province (SDAIT-10-06), the Fund of Shandong Agricultural Major Applied Technology Innovation, and the Key Research and Development Plan in Shandong Province (2016GGH3115).

\section{SUPPLEMENTARY MATERIAL}

The Supplementary Material for this article can be found online at: https://www.frontiersin.org/articles/10.3389/fvets. 2020.00576/full\#supplementary-material

Figure S1 | Purification of the fused Omp10 protein (14.6 kDa), Omp28 protein (28 kDa), and L7/L12 protein (14 kDa). M, Page ruler pre-stained protein ladder; lane 1, purified Omp10 protein (E. coll); lane 2, purified Omp28 protein (E. coli); lane 3, purified L7/L12 protein (E. coli).

Table S1 | Primers list of genes (E. coli prokaryotic expression).

Table S2 | Primers list of genes (P. pastoris eukaryotic expression). 


\section{REFERENCES}

1. Tabynov K, Ryskeldinova S, Sansyzbay A. An influenza viral vector Brucella abortus vaccine induces good cross-protection against Brucella melitensis infection in pregnant heifers. Vaccine. (2015) 33:3619-23. doi: 10.1016/j.vaccine.2015.06.045

2. Van d HC, De BM, Zorreguieta A, Letesson JJ, De BX. The Brucella pathogens are polarized bacteria. Microbes Infect. (2013) 15:998-1004. doi: 10.1016/j.micinf.2013.10.008

3. Yin D, Li L, Song D, Liu Y, Ju W, Song X, et al. A novel recombinant multiepitope protein against Brucella melitensis infection. Immunol Lett. (2016) 175:1-7. doi: 10.1016/j.imlet.2016.04.016

4. Zhang Y, Li T, Zhang J, Li Z, Zhang Y, Wang Z, et al. The Brucella melitensis M5-90 phosphoglucomutase (PGM) mutant is attenuated and confers protection against wild-type challenge in BALB/c mice. World $J$ Microb Biot. (2016) 32:58. doi: 10.1007/s11274-016-2015-6

5. Dorneles EMS, Lima GK, Teixeiracarvalho A, Araujo MSS, Martinsfilho $\mathrm{OA}$, Sriranganathan N, et al. Immune response of calves vaccinated with Brucella abortus S19 or RB51 and revaccinated with RB51. PLoS ONE. (2015) 10:e0136696. doi: 10.1371/journal.pone.0136696

6. Ivanov AV, Salmakov KM, Olsen SC, Plumb GE. A live vaccine from Brucella abortus strain 82 for control of cattle brucellosis in the Russian Federation. Anim Health Res Rev. (2011) 12:113-21. doi: 10.1017/S1466252311 000028

7. Shang D, Xiao D, Yin J. Epidemiology and control of brucellosis in China. Vet Microbiol. (2002) 90:165-82. doi: 10.1016/S0378-1135(02)00252-3

8. Liu L, Yu C, Wang C, Shao M, Yan Z, Jiang X, et al. Immuno-enhancement of Taishan Pinus massoniana pollen polysaccharides on recombinant Bordetella avium ompA expressed in Pichia pastoris. Microb Pathog. (2016) 95:5461. doi: 10.1016/j.micpath.2016.03.002

9. Avila-Calderon ED, Lopez-Merino A, Sriranganathan N, Boyle SM, Contreras-Rodriguez A. A history of the development of Brucella vaccines. Biomed Res Int. (2013) 2013:743509. doi: 10.1155/2013/743509

10. Goel D, Bhatnagar R. Intradermal immunization with outer membrane protein 25 protects Balb/c mice from virulent B. abortus 544 . Mol Immunol. (2012) 51:159-68. doi: 10.1016/j.molimm.2012.02.126

11. Simborio HL, Lee JJ, Bernardo Reyes AW, Hop HT, Arayan LT, Min W, et al. Evaluation of the combined use of the recombinant Brucella abortus Omp10, Omp19 and Omp28 proteins for the clinical diagnosis of bovine brucellosis. Microb Pathog. (2015) 83-4, 41-46. doi: 10.1016/j.micpath.2015.05.004

12. Ibañez AE, Smaldini P, Coria LM, Delpino MV, Pacífico LG, Oliveira SC. Unlipidated outer membrane protein Omp16 (U-Omp16) from Brucella spp. as nasal adjuvant induces a Th1 immune response and modulates the Th2 allergic response to cow's milk proteins. PLoS ONE. (2013) 8:e69438. doi: 10.1371/journal.pone.0069438

13. Wergifosse $\mathrm{PD}$, Lintermans $\mathrm{P}$, Limet JN, Cloeckaert A. Cloning and nucleotide sequence of the gene coding for the major 25-kilodalton outer membrane protein of Brucella abortus. J Bacteriol. (1995) 177:1911. doi: 10.1128/JB.177.7.1911-1914.1995

14. Vizcaíno N, Cloeckaert A, Zygmunt MS, Dubray G. Cloning, nucleotide sequence, and expression of the Brucella melitensis omp31 gene coding for an immunogenic major outer membrane protein. Infect Immun. (1996) 64:374451. doi: 10.1128/IAI.64.9.3744-3751.1996

15. Paquet JY, Diaz MA, Genevrois S, Grayon M, Verger JM, De BX. Molecular, antigenic, and functional analyses of Omp2b Porin size variants of Brucella spp. J Bacteriol. (2001) 183:4839. doi: 10.1128/JB.183.16.4839-4847.2001

16. Golshani M, Rafati S, Dashti A, Gholami E, Siadat SD, Oloomi M. Vaccination with recombinant L7/L12-truncated Omp31 protein induces protection against Brucella infection in BALB/c mice. Mol Immunol. (2015) 65:28792. doi: 10.1016/j.molimm.2015.01.009

17. Zhao Z, Li M, Luo D, Xing L, Wu S, Duan Y, et al. Protection of mice from Brucella infection by immunization with attenuated Salmonella enterica serovar typhimurium expressing A L7/L12 and BLS fusion antigen of Brucella. Vaccine. (2009) 27:5214-9. doi: 10.1016/j.vaccine.2009.06.075

18. Abkar M, Amani J, Sahebghadam LA, Nikbakht BG, Alamian S, Kamali M. Subcutaneous immunization with a novel immunogenic candidate (urease) confers protection against Brucella abortus and Brucella melitensis infections. Apmis. (2015) 123:667-75. doi: 10.1111/apm.12400
19. Ghasemi A, Jeddi-Tehrani M, Mautner J, Salari MH, Zarnani AH. Immunization of mice with a novel recombinant molecular chaperon confers protection against Brucella melitensis infection. Vaccine. (2014) 32:665966. doi: 10.1016/j.vaccine.2014.09.013

20. Luo D, Ni B, Li P, Shi W, Zhang S, Han Y, et al. Protective immunity elicited by a divalent DNA vaccine encoding both the L7/L12 and Omp16 genes of Brucella abortus in BALB/c Mice. Infect Immun. (2006) 74:2734. doi: 10.1128/IAI.74.5.2734-2741.2006

21. Luo DY, Li P, Xing L, Zhao GY, Shi W, Zhang SL. DNA vaccine encoding L7/L12-P39 of Brucella abortus induces protective immunity in BALB/c mice. Chin Med J. (2006) 119:331. doi: 10.1097/00029330-200602020-00012

22. Cassataro J, Pasquevich KA, Estein SM, Laplagne DA, Velikovsky CA, Barrera SD. A recombinant subunit vaccine based on the insertion of 27 amino acids from Omp31 to the N-terminus of BLS induced a similar degree of protection against B. ovis than Rev.1 vaccination. Vaccine. (2007) 25:443746. doi: $10.1016 /$ j.vaccine.2007.03.028

23. Golshani M, Rafati S, Siadat SD, Nejati-Moheimani M, Shahcheraghi F, Arsang A, et al. Improved immunogenicity and protective efficacy of a divalent DNA vaccine encoding Brucella L7/L12-truncated Omp31 fusion protein by a DNA priming and protein boosting regimen. Mol Immunol. (2015) 66:384-91. doi: 10.1016/j.molimm.2015.04.015

24. Tibor A, Decelle B, Letesson JJ. Outer membrane proteins Omp10, Omp16, and Omp19 of Brucella spp. are lipoproteins. Infect Immun. (1999) 67:49602. doi: 10.1128/IAI.67.9.4960-4962.1999

25. Tibor A, Wansard V, Bielartz V, Delrue RM, Danese I, Michel P, et al. Effect of omp10 or omp19 Deletion on Brucella abortus outer membrane properties and virulence in mice. Infect Immun. (2002) 70:5540. doi: 10.1128/IAI.70.10.5540-5546.2002

26. Salhi I, Boigegrain RA, Machold J, Weise C, Cloeckaert A, Rouot B. Characterization of new members of the group 3 outer membrane protein family of Brucella spp. Infect Immun. (2003) 71:4326-32. doi: 10.1128/IAI.71.8.4326-4332.2003

27. Tian M, Song M, Yin Y, Lian Z, Li Z, Hu H, et al. Characterization of the main immunogenic proteins in Brucella infection for their application in diagnosis of brucellosis. Comp Immunol Microbiol Infect Dis. (2020) 70:101462. doi: 10.1016/j.cimid.2020.101462

28. Cloeckaert A, Vizcaino N, Paquet JY, Bowden RA, Elzer PH. Major outer membrane proteins of Brucella spp.: past, present and future. Vet Microbiol. (2002) 90:229-47. doi: 10.1016/S0378-1135(02)00211-0

29. Chaudhuri P, Prasad R, Kumar V, Basavarajappa AG. Recombinant OMP28 antigen-based indirect ELISA for serodiagnosis of bovine brucellosis. Mol Cell Probes. (2010) 24:142-5. doi: 10.1016/j.mcp.2009.12.002

30. Oliveira SC, Splitter GA. Subcloning and expression of the Brucella abortus L7/L12 ribosomal gene and T-lymphocyte recognition of the recombinant protein. Infect Immun. (1994) 62:5201-4. doi: 10.1128/IAI.62.11.5201-5204.1994

31. Oliveira SC, Zhu Y, Splitter GA. Recombinant L7/L12 ribosomal protein and gamma-irradiated Brucella abortus induce a T-helper 1 subset response from murine $\mathrm{CD}^{+}{ }^{+} \mathrm{T}$ cells. J Immunol. (1994) 83:659-64.

32. Bertoni M, Kiefer F, Biasini M, Bordoli L, Schwede T. Modeling protein quaternary structure of homo- and hetero-oligomers beyond binary interactions by homology. SCI REP-UK. (2017) 7:10480. doi: 10.1038/s41598-017-09654-8

33. Guex N, Peitsch MC, Schwede T. Automated comparative protein structure modeling with SWISS-MODEL and Swiss-PdbViewer: a historical perspective. Electrophoresis. (2009) 30:S162-73. doi: 10.1002/elps.200900140

34. Waterhouse A, Bertoni M, Bienert S, Studer G, Tauriello G, Gumienny R, et al. SWISS-MODEL: homology modelling of protein structures and complexes. Nucleic Acids Res. (2018) 46:W296-303. doi: 10.1093/nar/gky427

35. Cui G, Zhong S, Yang S, Zuo X, Liang M, Sun J, et al. Effects of taishan Pinus massoniana pollen polysaccharide on the subunit vaccine of proteus mirabilis in birds. Int J Biol Macromol. (2013) 56:94-8. doi: 10.1136/vr.125.10.271

36. Wang ZM, Gao XM, Zhao QY, Zhao CL, Zuo XM, Liang MF, et al. Antivirus and antibactericidal effects of total flavones extracted from phoenix tree flower. Chin. J Vet. (2013) 33:272-6.

37. Wei K, Sun Z, Yan Z, Tan Y, Wang $H$, Zhu $X$, et al. Effects of Taishan Pinus massoniana pollen polysaccharide on immune response of rabbit haemorrhagic disease tissue inactivated vaccine 
and on production performance of Rex rabbits. Vaccine. (2011) 29:2530-6. doi: 10.1016/j.vaccine.2011.01.068

38. Yang Y, Wei K, Yang S, Li B, Zhang Y, Zhu F, et al. Co-adjuvant effects of plant polysaccharide and propolis on chickens inoculated with Bordetella avium inactivated vaccine. Avian Pathol. (2015) 44:24853. doi: 10.1080/03079457.2015.1040372

39. Guo F, Xue C, Wu C, Zhao X, Qu T, He X, et al. Immunoregulatory effects of Taishan Pinus massoniana pollen polysaccharide on chicks co-infected with avian leukosis virus and Bordetella avium early in ovo. Res Vet Sci. (2014) 96:260-6. doi: 10.1016/j.rvsc.2013.11.010

40. Zhao X, Liang M, Yang P, Guo F, Pan D, Huang X, et al. Taishan Pinus massoniana pollen polysaccharides promote immune responses of recombinant Bordetella avium ompA in $\mathrm{BALB} / \mathrm{c}$ mice. Int Immunopharmacol. (2013) 17:793-8. doi: 10.1016/j.intimp.2013.09.008

41. Wang H, Shan S, Wang S, Zhang H, Ma L, Hu L, et al. Fused IgY $\mathrm{Fc}$ and polysaccharide adjuvant enhanced the immune effect of the recombinant VP2 and VP5 subunits-a prospect for improvement of infectious bursal disease virus subunit vaccine. Front Microbiol. (2017) 8:2258. doi: 10.3389/fmicb.2017.02258

42. Wang Q, Miao Y, Xu Y, Meng X, Cui W, Wang Y, et al. Taishan Pinus Massoniana pollen polysaccharide inhibits the replication of acute tumorigenic ALV-J and its associated tumor growth. Vet Microbiol. (2019) 236:108376. doi: $10.1016 /$ j.vetmic.2019.07.028

43. Mwanza M, Kametler L, Bonai A, Rajli V, Kovacs M, Dutton MF. The cytotoxic effect of fumonisin B1 and ochratoxin A on human and pig lymphocytes using the Methyl Thiazol Tetrazolium (MTT) assay. Mycotoxin Res. (2009) 25:233-38. doi: 10.1007/s12550-009-0033-z

44. Mosmann T. Rapid colorimetric assay for cellular growth and survival: application to proliferation and cytotoxicity assays. J Immunol Methods. (1983) 65:55. doi: 10.1016/0022-1759(83)90303-4

45. Sha Z, Shang H, Miao Y, Huang J, Niu X, Chen R, et al. Recombinant lactococcus lactis expressing M1-HA2 fusion protein provides protective mucosal immunity against H9N2 avian influenza virus in chickens. Front Vet Sci. (2020) 7:153. doi: 10.3389/fvets.2020.00153

46. Lowry SF. Cytokine mediators of immunity and inflammation. Arch Surg. (1993) 128:1235-41. doi: 10.1001/archsurg.1993.01420230063010

47. Asherson GL, Ferluga J, Janossy G. Non-specific cytotoxicity by T cells activated with plant mitogens in vitro and the requirement for plant agents during the killing reaction. Clin Exp Immunol. (1973) 15:573-89.

48. Torti C, Prosperi M, Motta D, Digiambenedetto S, Maggiolo F, Paraninfo $\mathrm{G}$, et al. Factors influencing the normalization of $\mathrm{CD}^{+}$T-cell count, percentage and $\mathrm{CD} 4^{+} / \mathrm{CD}^{+}{ }^{+} \mathrm{T}$-cell ratio in HIV-infected patients on longterm suppressive antiretroviral therapy. Clin Microbiol Infect. (2012) 18:44958. doi: 10.1111/j.1469-0691.2011.03650.x

49. Fu S, Xu J, Li X, Xie Y, Qiu Y, Du X, et al. Immunization of mice with recombinant protein $\mathrm{CobB}$ or AsnC confers protection against Brucella abortus infection. PLoS ONE. (2012) 7:e29552-305. doi: 10.1371/journal.pone.0029552
50. Ghasemi A, Jeddi-Tehrani M, Mautner J, Salari MH, Zarnani AH. Simultaneous immunization of mice with Omp31 and TF provides protection against Brucella melitensis infection. Vaccine. (2015) 33:553238. doi: 10.1016/j.vaccine.2015.09.013

51. Araya LN, Elzer PH, Rowe GE, Enright FM, Winter AJ. Temporal development of protective cell-mediated and humoral immunity in BALB/c mice infected with Brucella abortus. J Immunol. (1989) 143:3330-7.

52. Oliveira SC, Sputter GA. CD8 ${ }^{+}$type 1 CD 44 hi CD 45 RBlo T lymphocytes control intracellular Brucella abortus infection as demonstrated in major histocompatibility complex class I- and class II-deficient mice. Eur J Immunol. (1995) 25:2551-7. doi: 10.1002/eji.1830250922

53. Pasquevich KA, Estein SM, Samartino CG, Zwerdling A, Coria LM, Barrionuevo $\mathrm{P}$, et al. Immunization with recombinant Brucella species outer membrane protein Omp16 or Omp19 in adjuvant induces specific $\mathrm{CD}^{+}$and $\mathrm{CD}^{+}{ }^{+} \mathrm{T}$ Cells as well as systemic and oral protection against Brucella abortus infection. Infect Immun. (2009) 77:436-45. doi: 10.1128/IAI. 01151-08

54. Yang Y, Wang L, Yin J, Wang X, Cheng S, Lang X, et al. Immunoproteomic analysis of Brucella melitensis and identification of a new immunogenic candidate protein for the development of brucellosis subunit vaccine. Mol Immunol. (2011) 49:175-84. doi: 10.1016/j.molimm.2011. 08.009

55. Chen R. Bacterial expression systems for recombinant protein production: E. coli and beyond. Biotechnol Adv. (2012) 30:11027. doi: 10.1016/j.biotechadv.2011.09.013

56. Martinez AM, Gonzalez MN, Garcia FE, Villaverde A. The functional quality of soluble recombinant polypeptides produced in Escherichia coli is defined by a wide conformational spectrum. Appl Environ Microbiol. (2008) 74:74313. doi: 10.1128/AEM.01446-08

57. Cereghino JL, Cregg JM. Heterologous protein expression in the methylotrophic yeast Pichia pastoris. FEMS Microbiol Rev. (2000) 24:45-66. doi: 10.1111/j.1574-6976.2000.tb00532.x

Conflict of Interest: HH was employed by company Shandong New Hope Liuhe Co., Ltd. HH is one of the inventors of a pending patent (CN-109486846-A) relevant to this work.

The remaining authors declare that the research was conducted in the absence of any commercial or financial relationships that could be construed as a potential conflict of interest.

Copyright () $2020 \mathrm{Zhu}$, Wang, Wang, Xu, Peng, Huang, Hu, Wei and Zhu. This is an open-access article distributed under the terms of the Creative Commons Attribution License (CC BY). The use, distribution or reproduction in other forums is permitted, provided the original author(s) and the copyright owner(s) are credited and that the original publication in this journal is cited, in accordance with accepted academic practice. No use, distribution or reproduction is permitted which does not comply with these terms. 